\title{
Patient Predictors of Surgical Candidacy in Elective Spine Disorders
}

\author{
Michael M.H. Yang, Godefroy Hardy St-Pierre, Stephan DuPlessis
}

\begin{abstract}
Background: The expansion of age-related degenerative spine pathologies has led to increased referrals to spine surgeons. However, the majority of patients referred for surgical consultation do not need surgery, leading to inefficient use of healthcare resources. This study aims to elucidate preoperative patient variables that are predictive of patients being offered spine surgery. Methods: We conducted an observational cohort study on patients referred to our institution between May 2013 and January 2015. Patients completed a detailed preclinic questionnaire on items such as history of presenting illness, quality-of-life questionnaires, and past medical history. The primary end point was whether surgery was offered. A multivariable logistical regression using the random forest method was used to determine the odds of being offered surgery based on preoperative patient variables. Results: An analysis of 1194 patients found that preoperative patient variables that reduced the odds of surgery being offered include mild pain (odds ratio [OR] 0.37, $p=0.008$ ), normal walking distance (OR $0.51, p=0.007)$, and normal sitting tolerance $(\mathrm{OR} 0.58, p=0.01)$. Factors that increased the odds of surgery include radiculopathy (OR 2.0, $p=0.001)$, patient's belief that they should have surgery (OR 1.9, $p=0.003)$, walking distance $<50 \mathrm{ft}(\mathrm{OR} 1.9$, $p=0.01$ ), relief of symptoms when bending forward (OR 1.7, $p=0.008)$ and sitting (OR 1.6, $p=0.009)$, works more slowly (OR 1.6 $p=0.01$ ), aggravation of symptoms by Valsalva (OR 1.4, $p=0.03)$, and pain affecting sitting/standing (OR 1.1, $p=0.001)$. Conclusions: We identified 11 preoperative variables that were predictive of whether patients were offered surgery, which are important factors to consider when screening outpatient spine referrals.
\end{abstract}

RÉSUMÉ: Les variables prédisant le recours à la chirurgie dans le cas de patients atteints de troubles de la colonne vertébrale. Contexte: L'augmentation des pathologies de la colonne vertébrale liées au vieillissement de la population a entrâné un accroissement des cas de patients adressés à des chirurgiens spécialistes de la colonne vertébrale. Cela dit, la majorité de ces patients n'ont pas besoin d'une telle intervention chirurgicale, ce qui entraîne une utilisation inefficace des ressources prévues pour les soins de santé. Cette étude vise donc, en regard de ces patients, à déterminer les variables préopératoires susceptibles de prédire ceux à qui l'on offrira finalement une chirurgie de la colonne vertébrale. Méthodes: Nous avons réalisé une étude de cohorte observationnelle portant sur des patients ayant été acheminés vers notre établissement entre mai 2013 et janvier 2015. Ces patients ont tout d'abord complété un questionnaire préclinique détaillé abordant notamment les aspects suivants : les antécédents d'apparition de leur maladie, le fait d'avoir rempli auparavant des questionnaires portant sur leur qualité de vie et leurs antécédents médicaux. Le principal indicateur ici évalué a été dans quelle mesure une intervention chirurgicale fut offerte. À l'aide la méthode dite de «forêts des arbres décisionnels » (random forest method), nous avons effectué une régression logistique à variables multiples afin de déterminer la probabilité qu'un patient se voit offrir une intervention chirurgicale. Pour ce faire, nous avons utilisé les variables préopératoires évoquées ci-dessus. Résultats: Parmi les 1194 patients analysés, nous avons déterminé qu'une douleur modérée $(\mathrm{RC} 0,37 ; \mathrm{p}=0,008)$, la capacité de parcourir à pied une distance normale $(\mathrm{RC} 0,51 ; \mathrm{p}=$ $0,007)$ et la capacité normale de tolérer une position assise $(\mathrm{RC} 0,58 ; \mathrm{p}=0,01)$ étaient les variables préopératoires qui réduisaient la probabilité de se voir offrir une chirurgie. Parmi les variables augmentant au contraire la probabilité d'être acheminé vers un service de chirurgie, mentionnons les suivantes : être atteint de radiculopathie ( $\mathrm{RC} 2,0 ; \mathrm{p}=0,001)$; le fait qu'un patient estime qu'il devrait bénéficier d'une opération chirurgicale $(\mathrm{RC} 1,9 ; \mathrm{p}=0,003)$; une capacité de marche inférieure à plus ou moins 15 mètres $(50$ pieds $)(\mathrm{RC} 1,9 ; \mathrm{p}=$ $0,01)$; le soulagement des symptômes en se penchant vers l'avant $(\mathrm{RC} 1,7 ; \mathrm{p}=0,008)$ ou en s'asseyant $(\mathrm{RC} 1,6 ; \mathrm{p}=0,009)$; le fait de travailler plus lentement (RC 1,$6 ; p=0,01) ;$ l'aggravation des symptômes en lien avec la manœuvre de Valsalva $(\mathrm{RC} 1,4 ; p=0,03)$; et des douleurs associées au fait de s'asseoir et de se lever ( $\mathrm{RC} 1,1 ; \mathrm{p}=0,001)$. Conclusions: Au total, nous avons identifié 11 variables préopératoires qui peuvent nous aider à prédire dans quelle mesure des patients sont susceptibles de se voir offrir une intervention chirurgicale. Il est donc important d'en tenir compte au moment de sélectionner des patients externes ayant été acheminés vers un service de chirurgie en raison de troubles de la colonne vertébrale.

Keywords: Degenerative spine disease, Spine surgery, Spine surgery assessment, Surgical yield, Clinical scoring system doi:10.1017/cjn.2018.342

Can J Neurol Sci. 2019; 46: 96-101

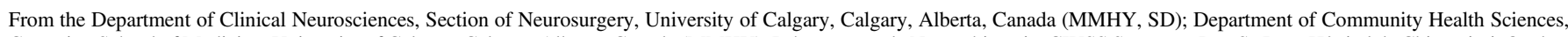

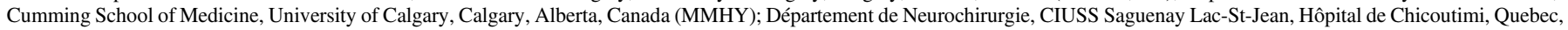
Canada (GHS).

Received May 16, 2018. Final Revisions Submitted July 23, 2018. Date of Acceptance August 19, 2018.

Correspondence to: Michael M.H. Yang, Department of Clinical Neurosciences, Section of Neurosurgery, 12 th Floor, 140329 th Street NW, Calgary, AB, Canada T2N 2 T9.

Email: minhan.yang@ucalgary.ca 


\section{INTRODUCTION}

Lumbar degenerative disease (lumbar spondylosis) and lowback pain (LBP) are common conditions, with more than 12 million Americans diagnosed each year, and $70 \%-85 \%$ of adults are affected by LBP at some point in their lifetime. ${ }^{1,2}$ The sequelae of LBP are among the leading causes of functional incapacity and a familiar source of chronic disability in the working years. ${ }^{3}$ Similarly, cervical degenerative diseases (cervical spondylosis) can cause neck pain and arm pain or spinal cord compression resulting in functional disability. Furthermore, with the expanding and aging population, increasing number of patients are suffering from degenerative spine diseases, leading to increased referral to spine surgeons by primary care physicians. ${ }^{2-4}$ However, up to $85 \%$ of referrals to spine surgeons are not surgical candidates, leading to inefficient use of healthcare resources. ${ }^{5}$

In the Canadian healthcare system, the limited number of spine surgeons available to meet the increased demand of referrals has caused a ballooning in wait time. ${ }^{6-9}$ Long wait times for consultation entails increased cost for both individuals and society, including lost work time, psychological distress, and decreased productivity. ${ }^{10}$ The decision on whether to offer surgery is often based on patient history, signs and symptoms, and functional metrics that are consistent with a surgical pathology and an expected favorable response to surgery. However, information included in primary care physician referrals are often inadequate to help triage patients effectively. Innovative strategies such as nonphysician clinician spinal triage programs have been developed and have been proven to be successful. ${ }^{7}$ However, triage systems such as these are costly and may not be accessible to spine surgeons. ${ }^{11}$ To tackle this issue, the Spine Triage and Assessment Clinic (STAC) at the University of Calgary developed an electronic survey called the patient-derived intake module; all referred patients are required to complete this module before seeing a spine surgeon. This survey collects a plethora of clinical variables such as patient demographics, comorbidities, functional capacity, history of presenting illness, previous surgeries, and various quality-of-life assessment questionnaires. The goal of this study is to determine which patient parameters from the patient-derived intake module are best able to predict whether a patient will have a high or low probability of being a surgical candidate. We also propose a clinical scoring system that may aid spine surgeons in triaging their outpatient referrals. By effectively triaging patients who have a low probability of being surgical candidates to other health professionals, wait times for patients who will benefit from surgery may be improved.

\section{Methods}

We performed an ambispective cohort study on patients referred to the Neurosurgery STAC at the Foothills Medical Centre, Canada, between May 2013 and January 2015. This clinic evaluates all outpatient referrals made to the neurosurgery spine service, as such patients were recruited in a consecutive manner. Patients requiring urgent surgical management are not referred to this clinic. All patients were consented and prospectively completed the patient-derived intake module, which was administered before the clinic visit. Variables collected included, but were not limited to, basic patient demographics, presenting symptoms, Short Form-12 (SF-12), patient disability questionnaire-9, McGill pain index, Charlson comorbidity index, visual analogue scale for pain, alleviating/aggravating factors, medications, occupational variables, and previous surgeries/injections. Details of the patient questionnaire can be found in Table 1 .

The primary outcome was whether surgery was offered. Patients seen through the STAC are initially evaluated by international medical graduates who have received Doctor of Medicine equivalent training. All cases are then reviewed by four complex spine subspecialty trained neurosurgeons, and the decision to offer surgery was determined by the surgeon. A case conference process to determine surgical candidacy was not used. Whether surgery was offered was retrospectively collected through electronic paper charts in December 2016 and updated in October 2017. Other variables that were collected retrospectively include the proportion of patients with MRI studies before the clinic, patients declining surgery, and patients who had their operation at the time of this study. Institutional approval was obtained through the Conjoint Health Research Ethics Board at the University of Calgary.

\section{Statistical Analysis}

Descriptive statistics was used to summarize included patients. A multivariable logistical regression using the random forest method was used to determine the odds of being offered surgery based on preoperative variables found in the patient-derived intake module. There were few missing data, which were imputed using random forest imputation. The remainder of preprocessing included removal of features with near-zero variance, scaling, and centering data. The feature space was filtered using additive construction of a random forest model, with the most important variables subsequently used to initialize a logistic regression model that was then tuned using recursive feature elimination (e.g., the most important features from the random forest model were used in the first logistic regression model, and the nonsignificant variables thereafter removed). Logistic regression was selected for interpretability. The level of significance was set at 0.05 , and $95 \%$ confidence intervals (CIs) were calculated for odds ratios (ORs). All statistical analyses were performed using RStudio v. 0.99.489.

\section{Results}

A total of 1194 unique patients were included in the analysis. The mean age was 53.3 years (SD: 14), and 626 (52.4\%) patients were male. The most common location of presenting pathology was in the thoracolumbar $(68.5 \%)$ and cervical regions $(30.0 \%)$. Twenty-six percent of patients were offered surgery, and among them $65(20.9 \%)$ patients declined surgery. At the time of outcomes data collection, $58.4 \%$ of patients who were offered surgery had received their operation (October 2017). The majority of patients $(89.2 \%)$ obtained an MRI before their clinic visit. Table 2 describes the baseline characteristics of the included patients.

\section{Predictors of Surgical Candidacy}

We found 11 independent significant preoperative patient factors that either increased or decreased the odds of patients being offered surgery. According to the multivariable model, the patient factors that reduced the odds of surgery being offered include the following: mild pain (OR 0.37 [95\%CI 0.17-0.74], $p=0.008$ ), normal walking distance (OR 0.51 [95\%CI 0.29-0.84], $p=0.007$ ), and normal sitting tolerance (OR 0.58 [95\%CI 0.38 - 


\section{Table 1: Patient-derived intake module questionnaire}

\begin{tabular}{l}
\hline Demographics \\
\hline 1. Name \\
\hline 2. Date \\
\hline 3. Email \\
\hline 4. Postal code \\
\hline 5. Health insurance \\
\hline 6. Date of birth \\
\hline 7. Sex \\
\hline 8. Hand dominance \\
\hline 9. Height (ft) \\
\hline 10. Weight (lbs) \\
\hline 11. Body mass index \\
\hline Comorbidities
\end{tabular}

12. Charlson comorbidity index

13. Smoking

\section{Alcohol}

Past medical history

\begin{tabular}{l} 
15. Past surgeries \\
\hline 16. Past injuries \\
\hline 17. Allergies \\
\hline Medications \\
\hline 18. Medications (frequency) \\
\hline a. Over-the-counter \\
\hline b. Anti-inflammatories \\
\hline c. Muscle relaxants \\
\hline d. Opioids \\
\hline e. Antidepressants \\
\hline f. Neuroleptics \\
\hline g. Other prescription medications \\
\hline Clinical problem
\end{tabular}

Clinical problem

19. Primary presenting illness

20. Primary symptomatic area

21. Description of primary symptoms

22. McGill pain index

23. Visual analogue of pain-current

24. Best visual analogue of pain - in the past 4 weeks

25 . Worst visual analogue of pain

26. Walking distance (ft)

27. Sitting tolerance (minutes)

28. Standing tolerance (minutes)

Investigations and treatments

\begin{tabular}{l}
\hline 29. X-ray \\
\hline 30. CT \\
\hline 31. MRI \\
\hline 32. Bone scan \\
\hline 33. Electromyography and nerve conduction study \\
\hline 34. Electromyography and other \\
\hline
\end{tabular}

Table 1. Continued

\begin{tabular}{l} 
35. Physiotherapy \\
\hline 36. Chiropractic \\
\hline 37. Active release \\
\hline 38. Massage therapy \\
\hline 39. Acupuncture \\
\hline 40. Prolotherapy \\
\hline 41. Spine injections \\
\hline a. Facet block \\
\hline b. Parks block \\
\hline c. Root block \\
\hline d. Radiofrequency lesioning \\
\hline e. Steroid injection \\
\hline 42. Spine injection response \\
\hline Employment \\
\hline 43. Occupation \\
\hline 44. Current work status \\
\hline 45. Prior work status \\
\hline 46. Occupational demands \\
\hline 47. How does your primary complaint effect your work? \\
\hline Quality-of-life questionnaires \\
\hline 48. Patient disability questionnaire-9 \\
\hline 49. Short Form-12 \\
\hline Patient expectations \\
\hline 50. Most important reason for referral \\
\hline 51. Second most important reason for referral \\
\hline 52. Third most important reason for referral \\
\hline 53. Do you think you need surgery \\
\hline
\end{tabular}

\section{Table 2: Baseline characteristics of included patients $(n=1194)$}

\begin{tabular}{l|c}
\hline Age $($ mean, SD) & 53.3 years $(14.0)$ \\
\hline Male sex $(n, \%)$ & $626(52.4)$ \\
\hline Location of pathology $(n, \%)$ & $355(30.0)$ \\
\hline Cervical & $21(1.8)$ \\
\hline Thoracic & $818(68.5)$ \\
\hline Thoracolumbar & $310(26.0 \%)$ \\
\hline Offered surgery $(n, \%)$ & $65(20.9)$ \\
\hline Declined surgery $(n, \%)$ & $181(58.4)$ \\
\hline Total number of surgeries $(n, \%)$ & $1065(89.2 \%)$ \\
\hline Number of MRI $(n, \%)$ & $333(28 \%)$ \\
\hline Smokers $(n, \%)$ & $27.3(9.8)$ \\
\hline Body mass index in kg/m ${ }^{2}$ (interquartile range) & $117(9.8 \%)$ \\
\hline Daily opioid usage $(n, \%)$ & $4.7(2.7)$ \\
\hline Mean preoperative visual analogue scale pain in mm $(\mathrm{SD})$ &
\end{tabular}




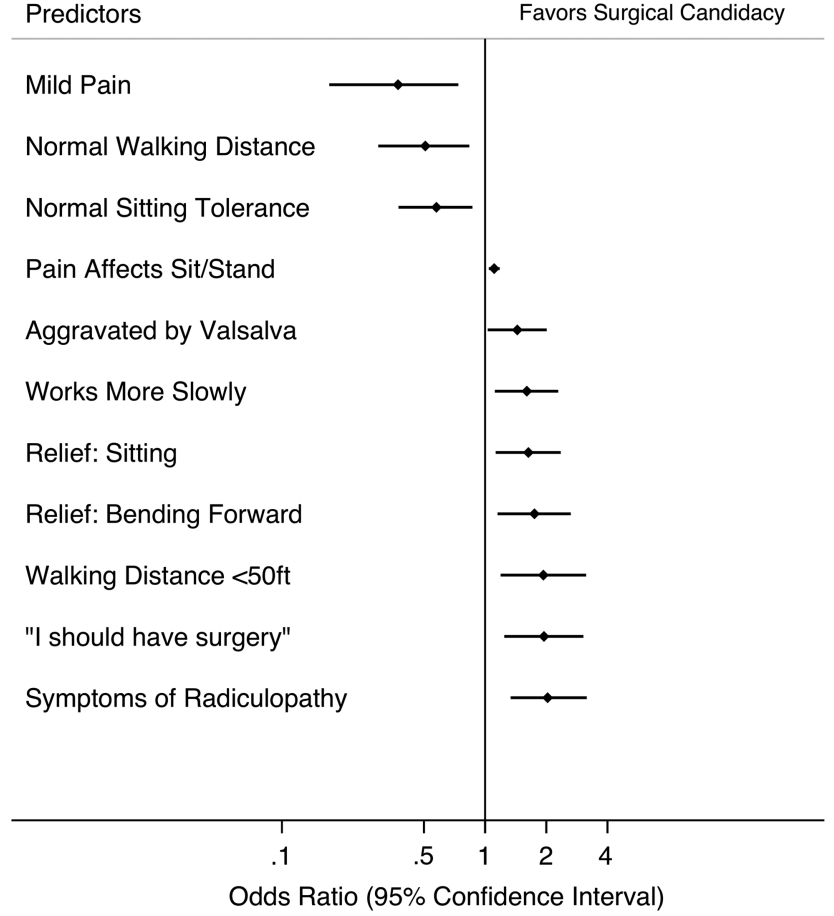

Figure 1: Significant preoperative patient factors that increase or decrease the odds of surgery being offered.

0.87], $p=0.01$ ) (Figure 1). Mild pain is defined as numeric rating scale or verbal rating scale for pain of 0 to 4 out of 10 . Normal sitting tolerance is defined as sitting tolerance $>60$ minutes.

Factors that increased the odds of surgery being offered included radiculopathy (OR 2.0 [95\% CI 1.3-3.2], $p=0.001$ ), patient's belief that they should have surgery (OR $1.9[95 \%$ CI 1.2-3.0], $p=0.003$ ), walking distance $<50 \mathrm{ft}$ (OR 1.9 [95\%CI 1.23.1], $p=0.01$ ), relief when bending forward (OR 1.7 [95\% CI 1.2-2.6], $p=0.008$ ), sitting (OR 1.6 [95\%CI 1.1-2.4], $p=0.009$ ), works more slowly (OR 1.6 [95\%CI 1.1-2.3], $p=0.01$ ), aggravation of symptoms by Valsalva (OR 1.4 [95\%CI 1.03-2.0], $p=0.03$ ), and pain affecting sitting or standing (OR 1.1 [95\%CI 1.04-1.2] $p=0.001$ ) (Figure 1). Other variables such as comorbidities, duration of symptoms, history of opioid therapy, pain quality, preoperative pain intensity, history of spinal injections, history of surgery, and items in the patient disability questionnaire and SF-12 were not predictive of significantly increasing or decreasing the odds of a patient being offered surgery.

\section{Discussion}

Spine surgery for degenerative conditions makes up a significant proportion of spine practices. In carefully selected patients, surgery can provide significant relief and positively affect the quality of life and physical function. ${ }^{4,12,13}$ However, the vast majority of referrals from primary care physicians have nonsurgical pathologies leading to inefficient use of healthcare resources. In this study, we found that patients who indicated that they have radicular symptoms had a strong belief that they should have surgery, and having a walking distance $<50 \mathrm{ft}$ increased their odds of being a surgical candidate by approximately two-fold. However, patients who report only mild pain, a normal walking distance, and a normal sitting tolerance had approximately 50\%$60 \%$ reduction in the odds of being a surgical candidate.

In Canada, the median wait time to see a neurosurgeon or orthopedic surgeon is 17.4 and 18.5 weeks, respectively. ${ }^{6}$ However, the clinically reasonable wait time as determined by specialist consensus is 5.1 and 11.8 weeks for neurosurgery and orthopedic surgery, respectively. ${ }^{6}$ Moreover, the median time between initial primary care referral to treatment is 24.7 and 39.6 weeks for neurosurgery and orthopedic surgery, respectively. ${ }^{6}$ Prolonged wait time to surgery can have detrimental effects on patient-perceived function and quality of life, not only while waiting for surgery but also negatively affecting surgical outcome. ${ }^{14}$ Given the aging population, these wait times are likely to get longer as more patients suffer from degenerative spine conditions unless innovative solutions are developed to direct care appropriately. Spine triage programs have been developed to tackle increased wait times and improve referral appropriateness. In a recent systematic review by McEvoy et al (2017), ${ }^{11}$ the authors identified 11 spine triage programs led by physiotherapists and three programs by nurses. ${ }^{1,7,15}$ Three of these programs were located in Canada: Saskatoon, Ottawa, and Toronto. 1,7,16,17 $^{-1}$ These nonphysician clinicians work either as a sole practitioner performing triage or in combination with a medical specialist or surgeon. These programs have been shown to be effective in reducing wait times, ranging between 3 and 54 weeks. $7,11,15,18$ The most marked improvement was reported by Curley et al $(2009)^{19}$, with a decrease in wait time for surgical review from 15 months to 6 weeks after introduction of the physiotherapist-led triage program. These programs have also cited high rates of identifying surgical candidates. ${ }^{11}$ The same authors reported that $97 \%$ of patients referred from their triage program had a surgical pathology. ${ }^{19}$ Although effective, these programs are resourceintensive to establish, costly to maintain, and inaccessible to many spine surgeons. ${ }^{11}$ As such, there continues to be a need for a simple, low-cost method to triage spine patients.

In this study, we found three patient factors that decreased the odds of someone being offered surgery (mild pain, normal walking distance, and normal sitting tolerance). These three clinical variables are an indication of the patient's functional status. It is unlikely for a patient to be offered surgery if they only have mild pain and have no functional disability when walking or sitting. On the other hand, patients complaining of paresthesia (numbness/ tingling) in their upper or lower extremity and pain exacerbated by Valsalva suggests that the patient has radiculopathy. ${ }^{20,21}$ Many different pathologies can cause radiculopathy, but a herniated disc or progressive spondylosis of the spine is most likely. The surgical outcomes of disc herniation causing radiculopathy are excellent, with a median time to recovery of 4 weeks compared with 12 weeks in the conservative therapy group, as reported by Peul et al (2007). ${ }^{22}$ Patients who have a walking distance of $<50$ feet and have relief when sitting or bending forward point to a patient with neurogenic claudication caused by lumbar canal stenosis. A study by Nadeau et al $(2013)^{23}$ showed that alleviation of leg pain when sitting and bending forward has a positive likelihood ratio of 3.8 and 1.7, respectively, for neurogenic claudication. Other variables such as working more slowly and pain affecting sitting/ standing are also indicators of the functional status of patients. It was interesting to find that the patient's belief of whether they should have surgery greatly influenced whether surgery was offered to the patient. The rationale for this is unclear, but this 
Table 3: Clinical scoring system for surgical candidacy in spine surgery

\begin{tabular}{|c|c|}
\hline & Score \\
\hline \multicolumn{2}{|l|}{ Negative predictors } \\
\hline Mild pain* & -3 \\
\hline Normal walking distance & -2 \\
\hline Normal sitting tolerance** & -2 \\
\hline \multicolumn{2}{|l|}{ Positive predictors } \\
\hline Symptoms of radiculopathy & 2 \\
\hline Walking distance $<50 \mathrm{ft}$ & 2 \\
\hline Relief when bending forward & 2 \\
\hline Relief when sitting & 2 \\
\hline Patient believes they should have surgery & 1 \\
\hline Works more slowly & 1 \\
\hline Pain aggravated by Valsalva & 1 \\
\hline Pain affecting sitting or standing & 1 \\
\hline \multicolumn{2}{|c|}{$\begin{array}{l}\text { Answering "no" yields a score of zero. Score interpretation: }-7 \text { to } 0 \text { - Lower chance } \\
\text { being a surgical candidate; } 1 \text { to } 12-\text { Higher chance of being a surgical candidate }\end{array}$} \\
\hline
\end{tabular}

could be a surrogate for patient's overall poor functional status and quality of life, thereby increasing their chance of being offered surgery. Cervical myelopathy was not found to be a significant predictor for surgical candidacy in this study. This is owing to the lack of myelopathy-specific questions in the patientderived intake module. Future iterations of this module will include myelopathy-specific questions.

It can be argued that the predictors for surgical candidacy elucidated in this study are not surprising, as they mainly point to patients with cervical or lumbar radiculopathy, and neurogenic claudication. The challenge is to devise a simple strategy to obtain this information from referring physicians and to decide on the likelihood of patients being a surgical candidate. To do this, we propose a clinical scoring system based on significant predictors found in this study. The OR for each predictor was rounded to the nearest integer and adjusted using subjective interpretation of the quality of the predictor to establish each variable's numeric clinical prediction score. ${ }^{24}$ For example, "patient's belief that they should have surgery" had an OR of 1.9; however, we subjectively modified its score to 1 as patients are usually poor at predicting whether they are surgical candidates. The inverse was taken for predictors that had ORs $<1$ and rounded to the nearest integer. ${ }^{24}$ The clinical scoring system can be found in Table 3. Predictors that decreased the odds of being surgical candidates were given negative scores (mild pain, normal walking distance, and normal sitting tolerance). Predictors that increased the odds of being surgical candidates were given positive scores (e.g., symptoms of radiculopathy and walking distance $<50 \mathrm{ft}$ ). The sum of scores can range between -7 and 12; positive total scores (1-12) suggest higher chance of being surgical candidates, whereas scores between -7 and 0 suggest a lower chance of being surgical candidates. Spine surgeons and nonphysician clinicians can request referring physicians to score their patients using this tool, which may lead to improvement in selection accuracy of surgical patients. However, like any clinical scoring system, this tool will need to be validated by a future prospective study.

The strength of our study includes the prospective nature in which data collection on patient variables was conducted. The large sample size included in this study allowed us to evaluate multiple preoperative patient variables without losing statistical power in our logistic regression analysis. We also proposed a simple clinical scoring system based on significant predictors found in this study that may aid spine surgeons in triaging their outpatient referrals. However, the findings from the present report should be interpreted in the context of the study design. The patient-derived intake module contained numerous preoperative variables that were included in the multivariable analyses, leading to increased probability of committing a type I error owing to multiple comparisons. This risk was minimized by using a recursive elimination method, where nonsignificant variables were removed with each subsequent logistic regression analysis. As inherent to all observational designs, residual confounding cannot be excluded. The primary outcome (whether surgery was offered) was determined by expert opinion of the surgeon evaluating the patient, which may not be equivalent to whether the patient needs or would benefit from surgery. This is mitigated by having four independent complex spine fellowship trained neurosurgeons staff the Spine Triage and Assessment Clinic. The patient-derived intake module was not designed to detect symptoms of myelopathy, and hence the predictors found in this study are not reliable in predicting surgical candidacy in myelopathy patients.

In conclusion, we identified 11 independent significant preoperative patient factors that were predictive of whether a patient will have higher or lower odds of being offered surgery. These predictors may be used to help spine surgeons more effectively triage their referrals and reduce the number of nonsurgical consultations. Future studies will be conducted to validate the proposed clinical scoring system.

\section{ACKNOWLEDGMENT}

The authors thank Abraham Nunes for his assistance in performing the statistical analyses for this project.

\section{Disclosures}

MMHY, GHS, and SD have nothing to disclose.

\section{Statement OF Authorship}

MMHY drafted the initial draft of the manuscript, performed data collection and data analyses, interpreted the study results, and critically reviewed the final draft of the manuscript.

GHS performed data collection and data analysis and critically reviewed the final draft of the manuscript.

SD conceptualized the study, provided mentorship and guidance, interpreted study results, and critically reviewed the final draft of the manuscript.

\section{FinANCIAL SuPPORT}

MMHY is supported by the Clinical Investigator Program at the University of Calgary and the Canadian Institute of Health Research. 


\section{REFERENCES}

1. Fourney DR, Dettori JR, Hall H, Hartl R, McGirt MJ, Daubs MD. A systematic review of clinical pathways for lower back pain and introduction of the Saskatchewan spine pathway. Spine (Phila Pa 1976). 2011;36(21 Suppl):S164-71.

2. Yavin D, Casha S, Wiebe S, et al. Lumbar fusion for degenerative disease: a systematic review and meta-analysis. Neurosurgery. 2017;80(5):701-15.

3. Driscoll T, Jacklyn G, Orchard J, et al. The global burden of occupationally related low back pain: estimates from the Global Burden of Disease 2010 study. Ann Rheum Dis. 2014;73(6):975-81.

4. St-Pierre GH, Yang MH, Bourget-Murray J, Thomas KC, Hurlbert RJ, Matthes N. Performance indicators in spine surgery. Spine (Phila Pa 1976). 2018;43(4):275-80.

5. Murphy S, Blake C, Power CK, Fullen BM. The role of clinical specialist physiotherapists in the management of low back pain in a spinal triage clinic. Ir J Med Sci. 2013;182(4):643-50.

6. Barua B, Esmail N. Waiting your turn: wait times for health care in Canada, 2013 report. 2013.

7. Bath B, Grona SL, Janzen B. A spinal triage programme delivered by physiotherapists in collaboration with orthopaedic surgeons. Physiother Can. 2012;64(4):356-66.

8. Bath B, Pahwa P. A physiotherapy triage assessment service for people with low back disorders: evaluation of short-term outcomes. Patient Relat Outcome Meas. 2012;3:9-19.

9. Robertson-Steel I. Evolution of triage systems. Emerg Med J. 2006;23(2):154-5.

10. Salomon JA, Vos T, Hogan DR, et al. Common values in assessing health outcomes from disease and injury: disability weights measurement study for the Global Burden of Disease Study 2010. Lancet. 2012;380(9859):2129-43.

11. McEvoy C, Wiles L, Bernhardsson S, Grimmer K. Triage for patients with spinal complaints: a systematic review of the literature. Physiother Res Int. 2017;22(1):e1639.

12. Gibson JN, Grant IC, Waddell G. Surgery for lumbar disc prolapse. Cochrane Database Syst Rev. 2000(3):CD001350.
13. Gibson JN, Waddell G, Grant IC. Surgery for degenerative lumbar spondylosis. Cochrane Database Syst Rev. 2000(3):CD001352.

14. Freeman BJ. The impact of surgical wait time on patient-based outcomes in posterior lumbar spine surgery (by J. Braybrooke et al.). Eur Spine J. 2007;16(11):1840-1.

15. Paskowski I, Schneider M, Stevans J, Ventura JM, Justice BD. A hospital-based standardized spine care pathway: report of a multidisciplinary, evidence-based process. J Manipulative Physiol Ther. 2011;34(2):98-106.

16. Sarro A, Rampersaud YR, Lewis S. Nurse practitioner-led surgical spine consultation clinic. J Adv Nurs. 2010;66(12):2671-6.

17. Simon D, Coyle M, Dagenais S, O'Neil J, Wai EK. Potential triaging of referrals for lumbar spinal surgery consultation: a comparison of referral accuracy from pain specialists, findings from advanced imaging and a 3-item questionnaire. Can J Surg. 2009;52(6):473-80.

18. Crossley L, Mueller L, Horstman P. Software-assisted spine registered nurse care coordination and patient triage-one organization's approach. J Neurosci Nurs. 2009;41(4):217-24.

19. Curley A, Cassells M, Cooke G, Dowling F. Physiotherapy-led low back pain triage: results of the first two years. Physiotherapy Ireland. 2004;25(2):3-9.

20. Kawakami M, Tamaki T, Hayashi N, Hashizume H, Nishi H. Possible mechanism of painful radiculopathy in lumbar disc herniation. Clin Orthop Relat Res. 1998;351:241-51.

21. Rubinstein SM, Pool JJ, van Tulder MW, Riphagen II, de Vet HC. A systematic review of the diagnostic accuracy of provocative tests of the neck for diagnosing cervical radiculopathy. Eur Spine J. 2007;16(3):307-19.

22. Peul WC, van Houwelingen HC, van den Hout WB, et al. Surgery versus prolonged conservative treatment for sciatica. $\mathrm{N}$ Engl $\mathrm{J}$ Med. 2007;356(22):2245-56.

23. Nadeau M, Rosas-Arellano MP, Gurr KR, et al. The reliability of differentiating neurogenic claudication from vascular claudication based on symptomatic presentation. Can J Surg. 2013;56(6):372-7.

24. Tu JV, Naylor CD. Clinical prediction rules. J Clin Epidemiol. 1997;50(6):743-4. 